\title{
Analysis of an Extensible Teaching Mode for Cultivating College Students into Innovative Talents
}

\author{
https://doi.org/10.3991/ijet.v16i10.22751 \\ Changliang Li $\left.{ }^{\square}\right)$, Hui Liu \\ Yantai Nanshan University, Yantai, China \\ lichangliang2021@163.com
}

\begin{abstract}
The competition between countries is essentially the competition of innovative talents. However, China now faces multiple problems in the cultivation of innovative talents: the talents are weak in innovation ability; the highlevel innovative talents are not sufficient; neither the quality or level of talents fully meet the demand of social and economic development. As a result, it is urgent for colleges to renovate the cultivation mode of innovative talents. Focusing on the cultivation of innovative talents majoring in architectural design, this paper thoroughly analyzed the extensible teaching mode for cultivating college students into innovative talents. Firstly, a questionnaire survey on relevant issues was carried out among employers and college graduates. The survey results revealed several problems with the innovative talent training in Chinese colleges, namely, the irrational curriculum design, the narrow scope of training objectives, and the lack of diverse teaching methods. Results verified, the employers are not highly satisfied with the innovative talents, especially the newly graduated ones. These problems are attributable to the weak professional development ability, poor teamwork ability, and insufficient innovation ability. To solve these problems, the authors analyzed and expounded the extensible teaching mode for the cultivation of innovative talents from four aspects: teaching content scope, teaching methods, teaching space, and appraisal. The research findings enrich the evidence of innovative talent training in Chinese colleges, providing a reference for improving the training quality of innovative talents.
\end{abstract}

Keywords - Innovative talents, talent training, extensible teaching mode

\section{Introduction}

With the constant development of countries around the globe, now the quality and quantity of innovative talents have become a measure for the overall strength of a country. In China, improving independent innovation ability and creating an innovative country is an important national development strategy. As the industrial structure is upgrading and the economy is developing at an astonishing pace, China's demand for innovative talents is becoming increasingly urgent. However, at present, China is facing the reality of insufficient innovative talent reserves, weak innovation ability, and unsatisfactory talent quality and level, and all these issues are greatly restricting the future development of China. Higher educational schools such as colleges and universities are 
the front of innovative talent cultivation; to promote technological advancement and economic prosperity and meet Chinese society's requirements for innovative talents, these schools must make greater efforts to strengthen quality education and reform the training mode of innovative talents.

In developed countries such as Europe and the United States, the research on innovative talents started earlier, but each country has different views on the meaning of innovative talents. For example, Japanese scholars believe that anyone who can conceive and create something valuable can be called an innovative talent [1]. American scholars define innovative talents according to the characteristics of creativity [2]. In 2006, the International 21 st Century Education Committee proposed criteria for judging innovative talents from seven aspects including adaptability, creativity, initiative, and entrepreneurship, etc. [3]. In China, the research on innovative talents started in the 1970 s, so far, domestic scholars have studied and analyzed the connotation and characteristics of innovative talents from different perspectives. The cultivation of innovative talents in Chinese colleges has gone through three stages: the first stage is from the 1980 s to the 1990s, during this period, the cultivation of innovative talents in Chinese colleges is at the start-up stage, some colleges in China had set a few innovation-related courses, but the cultivation of talents had not been well recognized or understood [4]. The second stage is the mid-1990s, during this period, under the guidance of the strategies of rejuvenating China through science and education and making China a powerful country through talents, the talent training mode in Chinese colleges entered a fastdeveloping stage, and various talent training modes, theories and practical studies had emerged accordingly [5]. The third stage began with the 17th National Congress of the Communist Party of China, under the guidance of the strategy of improving independent innovation ability and building an innovative country, the cultivation of innovative talents gradually moved to a mature stage; however, due to the influence of many factors, there're various problems with the innovative talent cultivation works in China [6].

The core of extensible teaching mode is the talent training objectives, aiming at the requirements of talent training, the extensible teaching mode extents the teaching in various aspects of teaching content, teaching forms, teaching methods, teaching time, and teaching space, thereby expanding students' knowledge scope and the channels for them to acquire knowledge, optimizing their learning methods, cultivating good learning habits, and exerting their personalities [7]. In view of these concerns, based on above analysis, this paper took the cultivation of innovative talents majoring in architectural design as an example to analyze and discuss the extensible teaching mode for cultivating college students into innovative talents, in the hopes of providing a useful reference for improving the training quality of innovative talents.

\section{Problems with Innovative Talent Training in Chinese Colleges}

To fully reveal the actual situations of innovative talent training in Chinese colleges, this study conducted both online survey and paper questionnaires to investigate related 
issues about innovative talent training in Chinese colleges from two perspectives of employers (enterprises) and employees (college graduates). The employers are mainly large and medium-sized enterprises, including private enterprises, state-owned enterprises, and foreign-funded enterprises; the investigated employees are college graduates graduated between 2009 and 2019 and they are now engaging in various industries. On the employer side, a total of 214 valid questionnaires were collected; while on the employee side, a total of 983 valid questionnaires were returned; after sorting out and analyzing these questionnaires, following results were obtained:

\subsection{Employers' demand for innovative talents and their satisfaction with college graduates}

1. Employers' demand for innovative talents

Figure 1 shows the survey results of the qualities that employers think the innovative talents should have. According to the figure, these qualities from high to low recognition level are: team work, professionalism, keen insight, innovative knowledge, and innovative will.

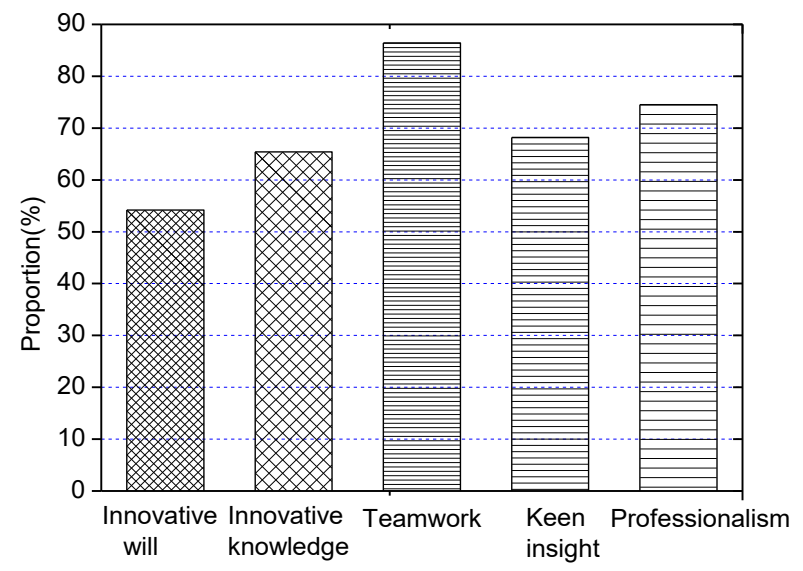

Fig. 1. Qualities that employers think the innovative talents should have

\section{Employers' satisfaction with innovative talents}

Figures 2 and 3 respectively show the survey results of the employers' overall satisfaction with innovative talents and their satisfaction with various qualities. According to the figure, the employers are not that satisfied with innovative talents, especially those who have just graduated. The quality with the lowest employer satisfaction $32.6 \%$ is the professional development ability. Generally, graduates begin to show gaps in their professional development ability after three years of working, employees with a weak professional development ability have limited contribution to the enterprise, they can only do basic works and have no advantage in promotion. Qualities with the second and 
third lowest satisfaction are teamwork ability (38.5\%) and insufficient innovation ability $(45.5 \%)$.

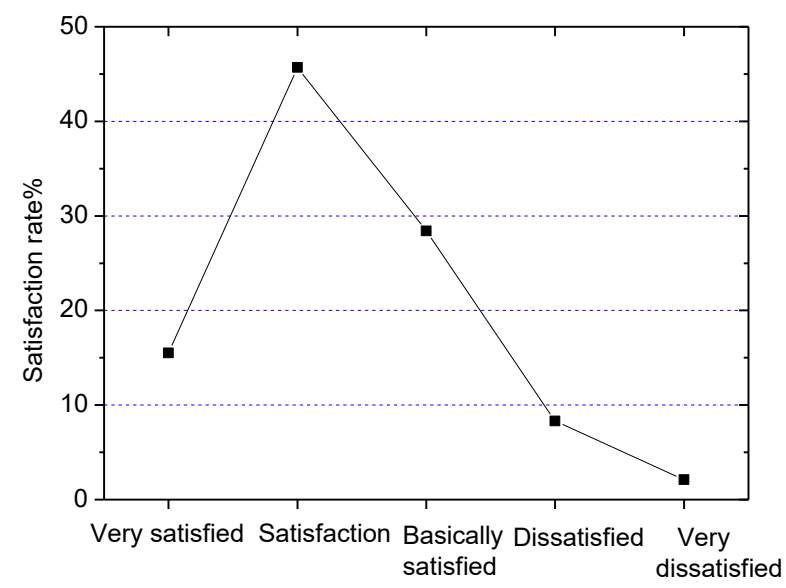

Fig. 2. Employers' overall satisfaction with innovative talents

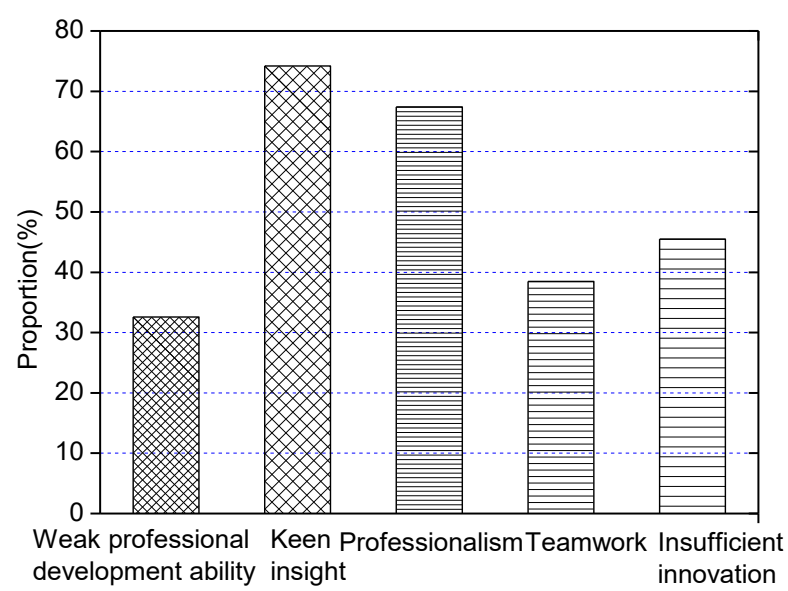

Fig. 3. Employers' satisfaction with innovative talents' qualities

\subsection{College graduates' evaluation on the training mode of innovative talents in colleges}

1. Irrational curriculum setting and narrow scope of training objectives

Figure 4 shows the survey results of college graduates' satisfaction with curriculum setting. It can be seen from the figure that although $82 \%$ of the respondents are very satisfied, satisfied or basically satisfied with curriculum setting in their schools, still, 
$14.6 \%$ and $3.4 \%$ of them expressed dissatisfaction or very dissatisfaction with curriculum setting.

The survey results of bottlenecks restricting the improvement of college graduates' innovation ability show that graduates believe that the single knowledge structure, poor hands-on ability, weak innovation awareness, and lack of solid professional knowledge are the four main factors restricting their innovation ability, as shown in Figure 5.

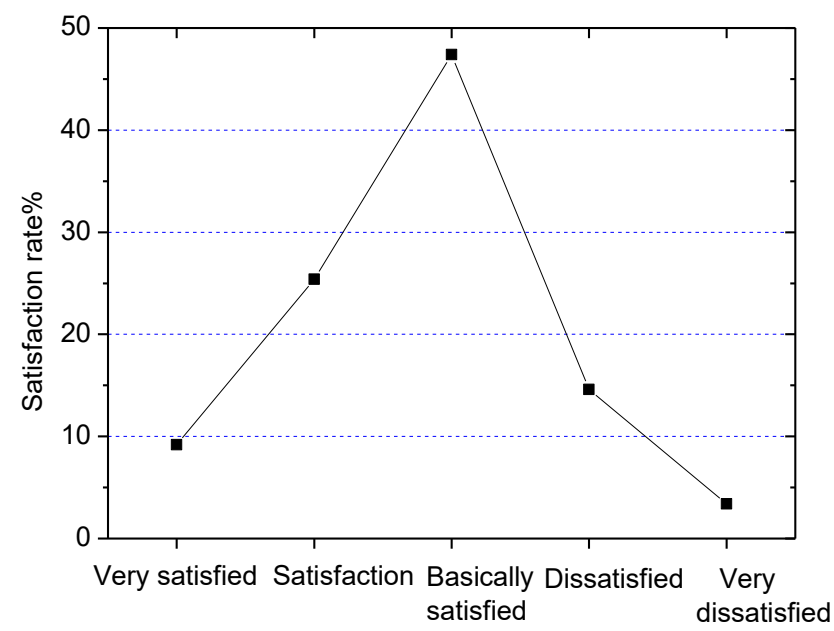

Fig. 4. College graduates' satisfaction with curriculum setting

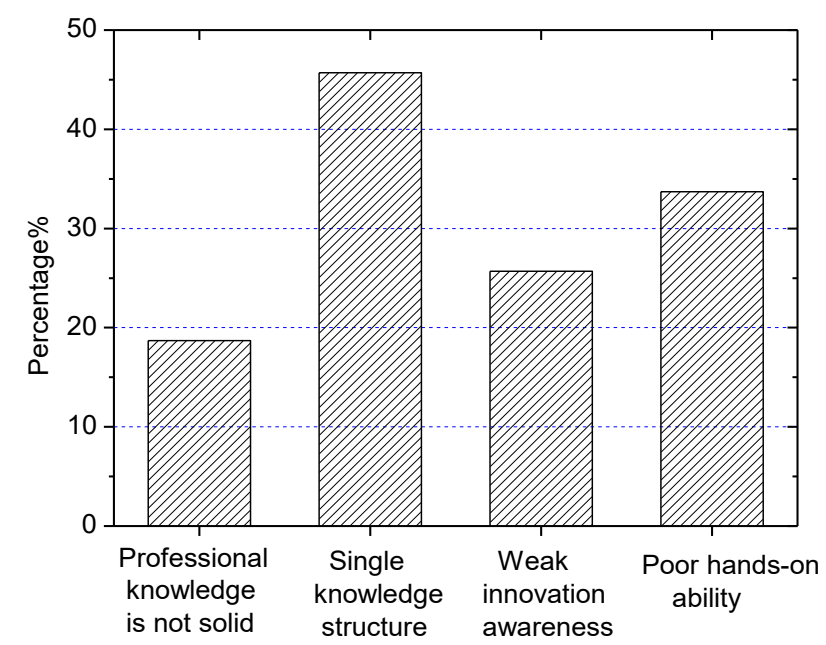

Fig. 5. Bottlenecks restricting the improvement of college graduates' innovation ability

Further summary and analysis of the interview results suggest that the irrational curriculum setting and the narrow scope of training objectives are the main problems for 
the cultivation of innovative talents in Chinese colleges. The specific manifestations include the undiversified curriculum system; narrow knowledge scope of the curriculum system; few interdisciplinary courses, comprehensive courses, and creative courses; small proportion of elective courses; students have little right to choose courses by themselves; large proportion of theoretical courses; few forms and small proportion of practical teaching links. All these problems have limited graduates' employment directions and professional abilities. As a result, the society's demand for innovative talents could not be met, and it has severely restricted the sustainable development of students' careers.

\section{Lack of diverse teaching methods}

Figure 6 shows the survey results of college teachers' main teaching methods when the respondent graduates were on campus. It can be seen from the figure that current college teachers still take the traditional teaching methods as the main teaching methods, accounting for $68.5 \%$. Project teaching, situational teaching, and other teaching methods account for only about $30 \%$, and classroom teaching seldom has teacher-student interactions. Students haven't taken the dominant role in study, they are in a passive learning state, they can pass exams by simply memorizing the knowledge points taught by teachers, which has resulted in that students have not developed good thinking habits or hard-working learning methods, let alone the innovative thinking or the innovation awareness.

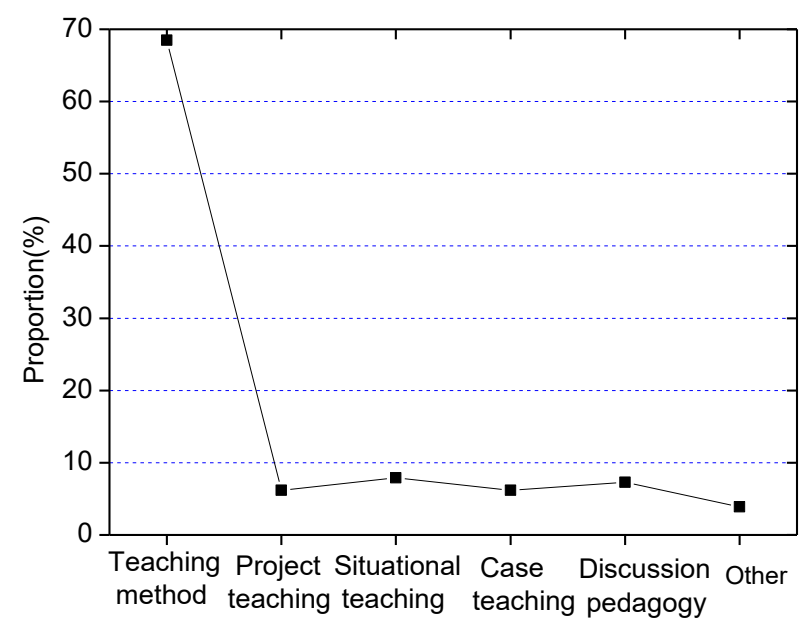

Fig. 6. Survey results of teachers' teaching methods 


\section{Analysis of the Extensible Teaching Mode for the Cultivation of Innovative Talents}

\subsection{The cultivation of innovative talents majoring in architectural design}

1. Training objectives of innovative talents majoring in architectural design

Innovative talents majoring in architectural design should be able to: master the basic knowledge, theories, and design methods of the architectural design discipline; have basic architectural design ability and basic R\&D ability; have creative thinking ability, an open vision, and a sense of social responsibility and teamwork spirit; have the concepts of sustainable development and cultural inheritance; engage in design works in architectural design institutions; have the adaptability to a variety of professions.

\section{Employment of innovative talents majoring in architectural design}

Figure 7 shows the statistical results of the job units of undergraduates majoring in architectural design in Guangdong Province from 2015 to 2020. According to the figure, although the main training target of the architectural design major is architectural designers, due to the influence of factors such as market demand and graduates' personal choices, the number of students who eventually engaged in architectural design jobs is quite limited. Most of them are now working in construction employer units or construction contractor units, and some students choose to continue their studies.

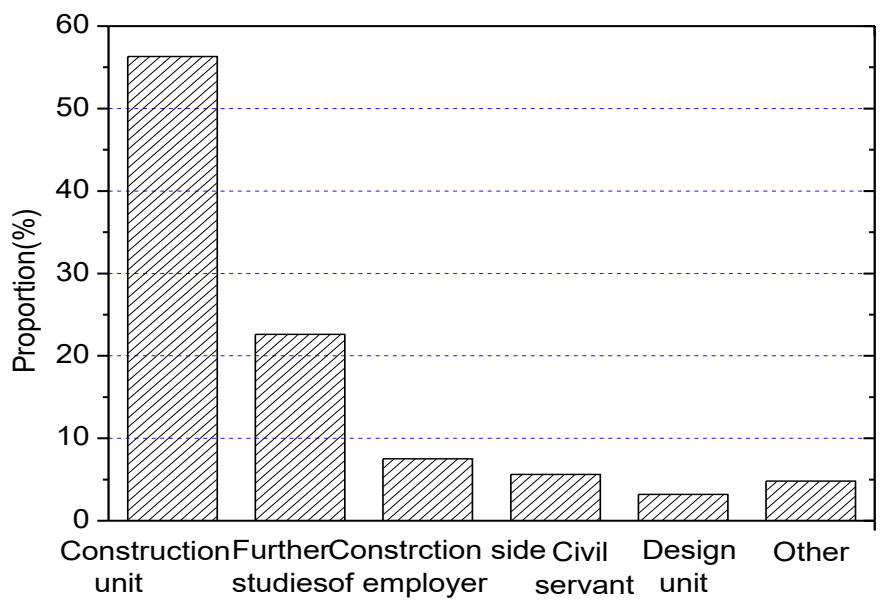

Fig. 7. Job units of undergraduates majoring in architectural design 
3.2 Analysis of the extensible teaching mode for the cultivation of innovative talents

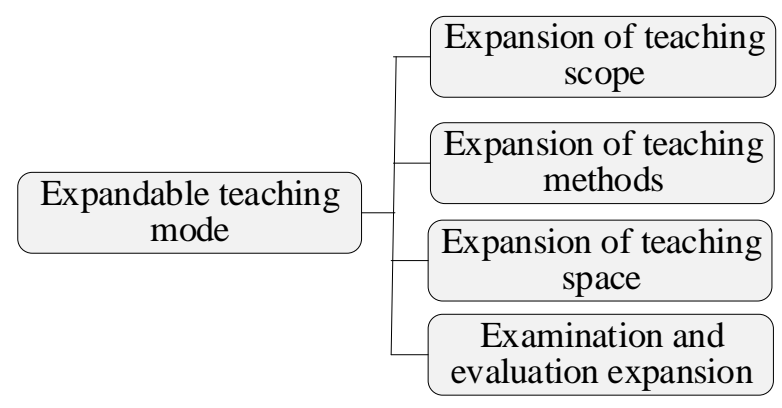

Fig. 8. The extensible teaching mode

The extensible teaching mode for the cultivation of innovative talents majoring in architectural design takes the cultivation of innovative architectural design talents as its core. Breaking through the traditional teaching framework, it extends the teaching in the four aspects of teaching content scope, teaching methods, teaching space, and appraisal, as shown in Figure 8. The architectural design major is extended from the architectural design field to the architectural science field, and the teaching is moved from the classroom to the natural and social environment. In this way, students' comprehensive understanding of the architectural design major and the architecture science could be improved, and students' comprehensive ability could be extended.

\section{Extension of teaching content scope}

Architecture is a comprehensive discipline involving economics, ecology, culture, and other disciplines. Architectural design is a sub-discipline of architecture. The discipline fields and responsibility scopes of modern architectural designers have gradually expanded and the connections between various disciplines are getting tighter. Figure 9 gives the discipline system of the architectural design major. In addition, survey results show that the employment industries of architectural design graduates have gradually expanded, therefore, the extension of the teaching content scope of architectural design major is not only to adapt to the requirements of the new era and the society for comprehensive-type and innovative-type talents, but also an inevitable trend for the future development of the architecture discipline [9]. 
Outward Open System for Architectural Design Major

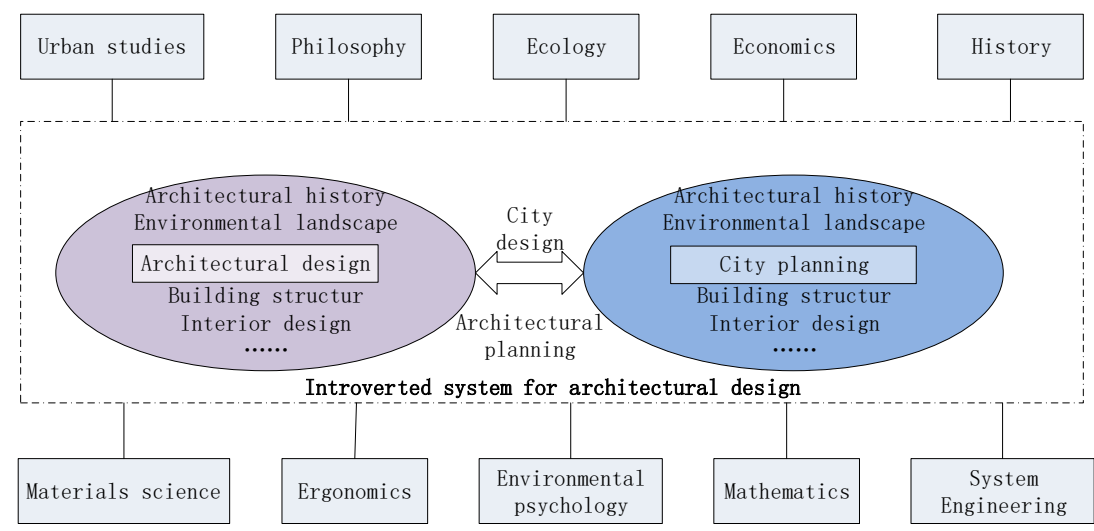

Fig. 9. Discipline system of the architectural design major

The extension of the teaching content scope includes two aspects: the extension of subject area, and the extension of design phase [10].

Extension of subject area: as shown in Figure 9, the inward system of the architectural design major includes not only the content directly related to architectural design such as architectural structure and construction standards, but also the content related to urban planning such as urban layout, urban transportation, and regional planning. Moreover, the outward system of architectural design major involves the content of economics, environmental science, color science, ergonomics, material science and other disciplines [11]. Therefore, when setting up courses for the architectural design major, the curriculum content should be extended, subjects related to the architectural design major should be set as mandatory or elective courses according to their importance degree. In particular, the types of elective courses should be enriched and students' rights to choose elective courses should be guaranteed so as to increase their knowledge reserves, enhance their professional development ability, and stimulate their innovative thinking. 


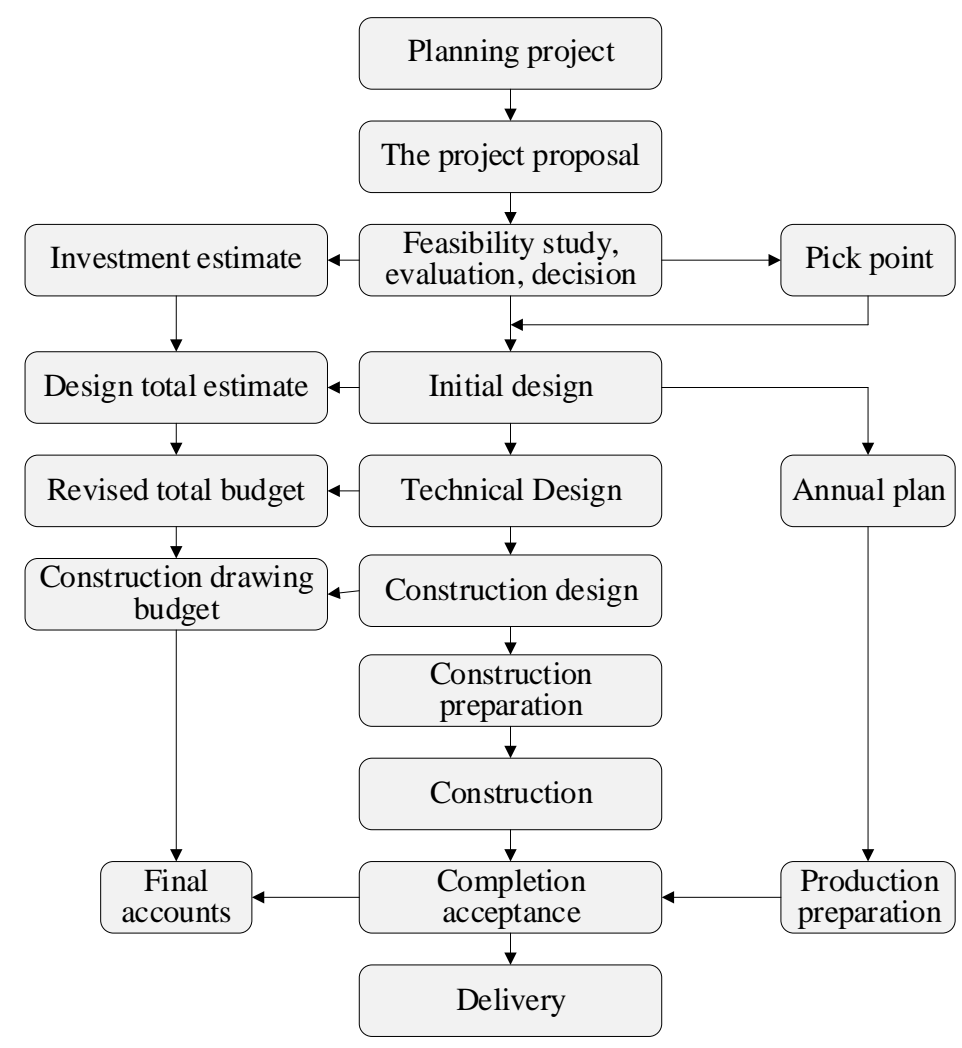

Fig. 10.Building construction procedure

Extension of design phase: the construction of a building involves multiple links such as planning, project approval, evaluation design, and construction, etc. These links are closely linked to form a complete building construction process, and architectural design is only one link in the whole process, Figure 10 gives a diagram of the building construction procedure [12]. During the teaching process, teachers should appropriately extend the design phase, besides explaining the relevant knowledge and methods of architectural design to students, they should also enable students to have an overall understanding of the building construction procedure, and allow them to learning about the main tasks and related knowledge involved in each stage of building construction through elective courses or self-study after class; in this way, students' vision could be broadened, their professional knowledge could be increased, and their comprehensive problem-solving ability could be enhanced. For example, when students majoring in architectural design are working on curriculum design or graduation design, teachers could combine architectural design with architectural planning and urban planning, lead students to conduct field surveys in planning areas, and give them overall trainings from block planning to architectural design. Such field trainings can extend the knowledge learning scope of students, and it is helpful for students to have a comprehensive and systematic understanding of the early stages of building construction. 


\section{Extension of teaching methods}

Classroom lecturing is still the main teaching method in Chinese colleges at present. Teachers control the lecturing content and teaching links of the entire classroom, while students are just passive knowledge receivers, and this teaching method is not conducive to stimulating students' learning enthusiasm or developing their abilities. The extension of teaching methods aims at highlighting the dominant role of students in the classroom, by rationally choosing the appropriate teaching methods and approaches, it directs at improving students' classroom participation and active thinking, cultivating learning habits of enjoying research and exploration, and promoting their innovative thinking and innovation ability. With the development of computer science and Internet technology, multimedia and various simulation technologies have been widely used in the field of architectural design, and these advanced modern techniques have enabled the teaching methods of architectural design to develop towards a diversified direction [13]. Figure 11 lists commonly-used teaching methods under the extensible teaching mode for the cultivation of innovative talents majoring in architectural design, including case teaching method, group cooperative teaching method, autonomous inquiry, visit and experience teaching method, and situational teaching method. Teachers should choose one or more teaching methods according to the specific content of a course. The combination of several teaching methods can stimulate students' learning enthusiasm, increase classroom participation, cultivate their comprehensive ability, and improve the quality and effectiveness of classroom teaching [14].

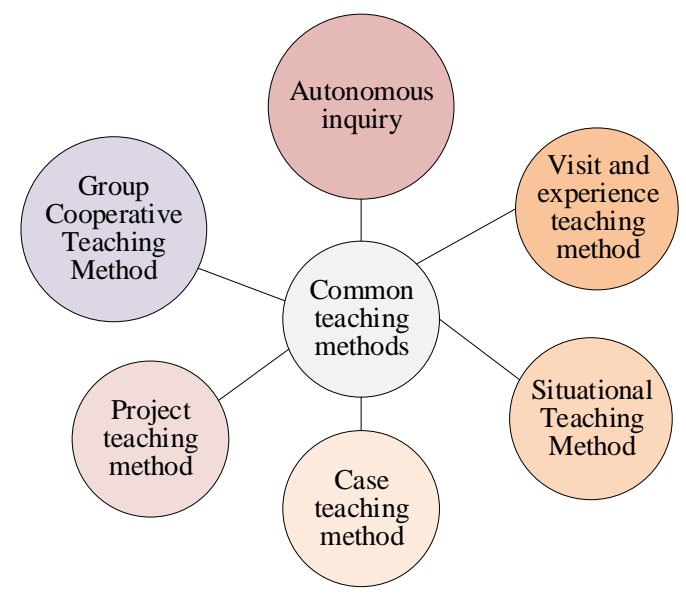

Fig. 11. Commonly-used teaching methods under the extensible teaching mode

\section{Extension of teaching space}

Buildings are existing in the objective environment, only showing a few photos and videos in classrooms cannot make students master the essence and connotation of the buildings. Therefore, we should allow students majoring architectural design to step out of the classroom, expand the teaching space, and focus on the combination of theory 
and practice. The extension of teaching space should break the traditional classroomoriented teaching idea and expand the teaching space to the natural and social environment, enabling students to perceive and learn through their own observation, discovery, feeling, and thinking; in this way, the efficiency of classroom teaching can be improved, and students can diverge their thinking [8].

For architectural design majors, visits and internships are the most direct ways to extend the teaching space. First, according to the teaching content, teachers can lead students to visit various types of buildings that have been built or under construction, help them understand the relevant knowledge of architectural design and master the basic structure and materials used in the buildings; at the same time, students could also learn about knowledge related to construction and engineering. Second, teachers can take actual design projects as teaching tasks and lead students to conduct field survey and investigation so as to inspire them to have a deeper understanding of the design projects through their own survey results and intuitive experience on the spot. Third, via school-enterprise cooperation, we could provide students with off-campus internship opportunities; each semester, we should organize students to study in cooperative enterprises for fixed positions and rotations, so that they can gradually master the knowledge of architectural design and related fields during practice; in this way, their teamwork ability, practical skills, and professionalism could be cultivated and enhanced [15].

\section{Extension of appraisal}

Appraisal is an important link in teaching and an important means to evaluate teachers' teaching effects and students' learning achievements. In the traditional teaching mode, paper examination is the main method of appraisal; in terms of the architectural design major, besides paper examination, some courses would include the results of curriculum design into the appraisal. Generally, teachers judge whether students are qualified or not through their final exam results, and schools judge teachers' teaching quality based on students' pass rate and excellent rate. However, the facts show that some students with excellent grades are not better than students with lower grades in design ability, professional development, or innovation ability [16].

Reasonable appraisal methods often have a positive effect on the development of students; therefore, the evaluation of students should not be limited to the final exam scores. Teachers should choose a variety of appraisal methods according to the content and characteristics of each course, and give detailed procedural appraisals to the learning process and learning ability of students. For example, teachers can include students' daily homework, teamwork and exchanges, learning attitudes, learning methods, and internship training results into the appraisal scope. Moreover, besides teacher's evaluation on students, various evaluation methods such as students' self-evaluation, mutual evaluation, and the internship enterprises' evaluation on the students could be adopted, so that the teachers can fully discover the merits and specialties of each student and encourage them to continue learning and make progress; at the same time, the students could understand their own shortcomings and determine new directions for their efforts [17]. 


\section{Conclusion}

The quality of innovative talents is directly related to a country's comprehensive strength and its future economy level. Aiming at problems existing in the cultivation of innovative talents in Chinese colleges, this paper studied the extensible teaching mode for the cultivation of innovative talents and drew the following conclusions:

1. The survey results of college graduates' evaluation on the talent training mode in Chinese colleges showed that, there are a few problems with the current innovative talent cultivation works in Chinese colleges, including irrational curriculum setting, narrow scope of training objectives, and lack of diverse teaching methods, etc.

2. The survey results of the employers' evaluation on the talent training mode in Chinese colleges showed that, the employers are not highly satisfied with the innovative talents, especially the newly graduated ones, and these problems are attributable to the weak professional development ability, poor teamwork ability, and insufficient innovation ability.

3. In response to the survey results, with the architectural design major as an example, this paper gave a detailed analysis and explanation of the extensile teaching mode for the cultivation of innovative talents from four aspects of teaching content, teaching methods, teaching space, and appraisal.

\section{$5 \quad$ References}

[1] Klapper, P., Butler, N.M. (1920). College teaching studies in methods of teaching in the college pot. American Mathematical Monthly, 92(2): 50. https://doi.org/10.1177/00220574 2009200217

[2] Nageswari, K.S., Malhotra, A.S., Kapoor, N., Kaur, G. (2004). Pedagogical effectiveness of innovative teaching methods initiated at the Department of Physiology, Government Medical College, Chandigarh. Advances in physiology education, 28(2): 51-58. https://doi. org/10.1152/advan.00013.2003

[3] Li, Z., Lowe, J. (2016). Mobile student to mobile worker: The role of universities in the 'war for talent'. British journal of sociology of education, 37(1): 11-29. https://doi.org/10.108 0/01425692.2015.1095636

[4] Chen, W.P., Lin, Y.X., Ren, Z.Y., Shen, D. (2021). Exploration and practical research on teaching reforms of engineering practice center based on 3I-CDIO-OBE talent-training mode. Computer Applications in Engineering Education, 29(1): 114-129. https://doi.org/ $10.1002 /$ cae. 22248

[5] Zhang, W., Zhang, S., Guo, S., Yang, Y., Chen, Y. (2017). Concurrent optimal allocation of distributed manufacturing resources using extended teaching-learning-based optimization. International Journal of Production Research, 55(3): 718-735. https://doi.org/10.1080/00 207543.2016.1203078

[6] Saleh, A.M., Al-Tawil, N.G., Al-Hadithi, T.S. (2012). Teaching methods in Hawler College of Medicine in Iraq: A qualitative assessment from teachers' perspectives. BMC medical education, 12(1): 1-6. https://doi.org/10.1186/1472-6920-12-59

[7] Fan, P. (2020). Application of deep learning and cloud data platform in college teaching quality evaluation. Journal of Intelligent \& Fuzzy Systems, 39(4): 5547-5558. https://doi.org/10.3233/JIFS-189036 
[8] Rovin, S., Packer, M.W. (1971). Evaluation of teaching and teachers at the University of Kentucky College of Dentistry. I. Development of evaluation criteria. Journal of dental education, 35(8): 496-501. https://doi.org/10.1002/j.0022-0337.1971.35.8.tb00408.x

[9] Zhou, X., Tian, L. (2019). An Empirical Study on the Satisfaction of Students in the Cultivation of Innovative Talents: Take E-marketing Course as an Example. Journal of Coastal Research, 93(SI): 866-869. https://doi.org/10.2112/SI93-123.1

[10] Dogra, N., Carter-Pokras, O. (2005). Stakeholder views regarding cultural diversity teaching outcomes: a qualitative study. BMC Medical Education, 5(1): 1-12. https://doi.org/10.11 $\underline{86 / 1472-6920-5-37}$

[11] Long, S., Zhao, X. (2020). Smart teaching mode based on particle swarm image recognition and human-computer interaction deep learning. Journal of Intelligent \& Fuzzy Systems, (Preprint), 39(4): 5699-5711. https://doi.org/10.3233/JIFS-189048

[12] Cismaru, L., Iunius, R. (2019). Bridging the Generational Gap in the Hospitality Industry: Reverse Mentoring-An Innovative Talent Management Practice for Present and Future Generations of Employees. Sustainability, 12(1): 1-38. https://doi.org/10.3390/su12010263

[13] Zhang, J.L. (2020). The Application of Human Comprehensive Development Theory and Deep Learning in Innovation Education in Higher Education. Frontiers in Psychology, 11: 1605. https://doi.org/10.3389/fpsyg.2020.01605

[14] Doonan, F., Taylor, L., Branduardi, P., Morrissey, J.P. (2018). Innovative training networks: overview of the Marie Skłodowska-Curie PhD training model. FEMS microbiology letters, 365(19): fny207. https://doi.org/10.1093/femsle/fny207

[15] Qian, H. (2010). Talent, creativity and regional economic performance: the case of China Annals of Regional Science, 45(1): 133-156. https://doi.org/10.1007/s00168-008-0282-3

[16] Radebaugh, L.H., Shields, J.C. (1984). A note on foreign language training and international business education in US colleges and universities. Journal of International Business Studies, 15(3): 195-199. https://doi.org/10.1057/palgrave.jibs.8490503

[17] Hurtado, S., Eagan, M.K., Tran, M.C., Newman, C.B., Chang, M.J., Velasco, P. (2011). "We do science here": Underrepresented students' interactions with faculty in different college contexts. Journal of social issues, 67(3): 553-579. https://doi.org/10.1111/j.1540$\underline{4560.2011 .01714 . x}$

\section{Authors}

Changliang Li was born in Linyi City, Shandong Province, China in December 1975. He graduated from the international relations major of the Institute of political science of Huazhong Normal University in 2007. Now, working in Yantai Nanshan University, Shandong Province, China. His research is mainly the higher education and the education of creation and innovation. He is an associate professor. Email: lichangliang2021@163.com

Hui Liu was born in Dezhou City, Shandong Province, China in Octoer 1979. She graduated from functional analysis major of School of Mathematical Sciences, Xiamen University in 2007. Now working in Yantai Nanshan University, Shandong Province, China. Hers research is mainly the higher education and the education of creation and innovation. She is a lecturer. Email: a445645889@163.com

Article submitted 2021-02-22. Resubmitted 2021-03-27. Final acceptance 2021-03-28. Final version published as submitted by the authors. 